\title{
Plasma Glucagon Levels in Normal Women during Pregnancy*
}

\author{
A.S. Luyckx, J. Gerard, U. Gaspard and P.J. Lefebvre \\ Div. of Diabetes. Inst. of Medicine and Dept. of Obstetrics and Gynecology. Univ. of Liège, Liège, Belgium
}

Received: March 26, 1975, and in revised form: September 1, 1975

\begin{abstract}
Summary. Increased plasma pancreatic glucagon concentrations have been reported during various states of decreased glucose tolerance. In vitro studies have demonstrated that human somatomammotropin stimulates glucagon release. The present investigation aimed at evaluating the role of plasma glucagon in the insulin resistance associated with normal pregnancy. Postprandial samples of plasma were obtained from 156 pregnant women between the 5 th and the 40th week of pregnancy and were assayed for blood glucose, plasma insulin, glucagon and free fatty acids. Plasma insulin showed a gradual increase during pregnancy, and reached its maximal values during the last trimester. A moderate but significant increase in plasma glucagon was present between the 16th and the 28 th week of gestation, whereas during the first and the last trimester of pregnancy its concentration was similar to that in non preg-
\end{abstract}

nant women. Intravenous glucose tolerance was performed during the last trimester and in a group of non pregnant control women. The slight decrease in glucose tolerance and the marked hyperinsulinemia associated with late pregnancy were accompanied by a more rapid and more pronounced decrease in plasma glucagon. A rapid and sustained decrease in glucagon was also observed when plasma FFA were raised by the intravenous administration of a triglyceride emulsion and heparin. These data suggest that glucagon is not involved in the insulin resistance associated with normal human pregnancy.

Key words: Free fatty acids, glucagon, glucose, glucose-tolerance, insulin, insulin-resistance, pregnancy.
It has been well demonstrated that plasma glucagon levels are abnormally high in most pathological conditions characterized by reduced glucose tolerance ( $\mathrm{Re}-$ view in 1 and 2). Several arguments support the theory that the reduced glucose tolerance under these conditions is due, at least in part, to the elevated glucagon levels [2]. It could thus be anticipated that the insulin resistance seen in normal pregnant women $[3,4,5]$ is also a result of abnormal glucagon secretion. The grounds for this assumption is supported by the observation that sommatomammotropin, or hPL, stimulates glucagon secretion in the isolated perfused rat pancreas [6]. In order to test this hypothesis, we measured, in the first part of this study, plasma glucagon levels in normal pregnant women. Glucagon secretion is controlled by several factors, including plasma glucose and free fatty acid (FFA) levels: high concentrations of these two substrates exercise a negative feedback effect on glucagon secretion (review in 7). Therefore, in the second part of this study, we

\footnotetext{
* Paper presented at the 9th Annual Meeting of the European Society for Clinical Investigation, Rotterdam, April 24-26, 1975 and published in abstract in the Eur. J. Clin. Invest. 5 (1975).
}

investigated the effectiveness of these feedback systems during the last trimester of pregnancy.

\section{Materials and Methods}

1. One hundred and fifty six blood samples were collected from 128 pregnant women at various stages of pregnancy (from the fifth week to term). All these women were of normal weight before pregnancy and had a normal weight gain and no glycosuria during pregnancy. No previous obstetrical or perinatal pathology was present in the women studied. Thirteen blood samples from 13 control women having a normal reproductive cycle were also collected. The mean age/height/weight values ( $\mathrm{m} \pm \mathrm{SEM}$ ) were as follows; controls: $25 \pm 1 \mathrm{yrs} / 164 \pm 1 \mathrm{~cm} / 57 \pm 3 \mathrm{~kg}$; first trimester: $25 \pm 1 \mathrm{yrs} / 160 \pm 1 \mathrm{~cm} / 57 \pm 2 \mathrm{~kg}$; second trimester: $27 \pm 2 \mathrm{yrs} / 155 \pm 1 \mathrm{~cm} / 60 \pm 2 \mathrm{~kg}$; third trimester: $26 \pm 1 \mathrm{yrs} / 157 \pm 1 \mathrm{~cm} / 69 \pm 2 \mathrm{~kg}$. The control and pregnant women were paired for weight (using the weight of the pregnant women before their pregnancy): 57 ( $\pm 3, \mathrm{SEM})$, for the controls and 57 ( \pm 1, SEM) for the pregnant women. In all cases, blood was drawn from an antecubital vein 2 to 4 hrs after a 
non-standardized lunch. The time of sampling was determined by the fact that the antenatal outpatient clinic takes place during the afternoon. The samples were analyzed for blood glucose, plasma FFA, insulin and glucagon (see below).

2. An intravenous glucose tolerance test (IVGTT) was performed in 12 control and in 8 normal pregnant women during the last trimester of pregnancy. The test was performed in the morning, following an overnight fast. A glucose load of $0.33 \mathrm{~g}$ per $\mathrm{kg}$ of body weight was injected into an antecubital vein, beginning at time 0 and lasting 3 minutes. Blood was drawn from an antecubital vein of the other arm at $-15,0,3$, $5,10,20,30,40,50$ and $60 \mathrm{~min}$ relative to the beginning of the glucose infusion. The average age of the pregnant women in this group was $26.9 \pm 3.4$ (SEM) years and that of the control group was $23.4 \pm 1.8$ (SEM) years.

3. An artificial rise in plasma $F F A$ was induced in six normal pregnant women during the last trimester of pregnancy, using a procedure previously described [8]. Here again, the test was performed in the morning after an overnight fast. Following a 15 min control period, a lipid emulsion (Lipiphysan egic ${ }^{\circledR}$, Montargis, France) was infused into an antecubital vein at a rate of $1 \mathrm{ml} / \mathrm{min}$ for $75 \mathrm{~min}$ using a Braun Infusomat ${ }^{\circledR}$. Fifteen min after the start of the infusion, $5000 \mathrm{U}$ of Heparin $^{\circledR}$ (Novo, Copenhagen) were injected intravenously in order to activate lipoprotein-lipase. Venous blood was drawn from an antecubital vein of the other arm at time 0 (before infusion) and 15, 30, $45,60,75,90,105,120,150$ and 180 min after the beginning of the infusion. The average age of the pregnant women of this group was $25.3 \pm 3.8$ years.

4. Assay procedures: Blood glucose was determined using Hoffman's method [9] adapted to the
Technicon Auto Analyzer. For free fatty acid and hormonal determinations, $4.5 \mathrm{ml}$ of blood were added to a chilled tube which contained $0.5 \mathrm{ml}$ of an aqueous solution made with $5000 \mathrm{U}$ of Trasylol ${ }^{\circledR}$ Bayer and 12 mg of $\mathrm{Na}_{2}$ EDTA per ml. The tubes were kept in an ice-cold bath until centrifugation, which was performed using arefrigerated centrifuge. Plasma was then separated and kept at $-20^{\circ} \mathrm{C}$. Plasma FFA levels were measured using the method of Dole and Meinertz [10]. Plasma insulin was assayed in duplicate using a modification [11] of the radioimmunoassay procedure of Hales and Randle [12]. Plasma glucagon was determined in duplicate using a procedure previously described [13] using antiserum $30 \mathrm{~K}$, kindly provided by Dr. R.H. Unger (Dallas), which is considered to be specific for glucagon ${ }^{1}$.

5. Statistical methods [15]: The Student's- $t$-test for non-paired data was used to determine the statistical significance of the differences observed in the concentrations of substances in the samples obtained from controls and from pregnant women at the various stages of pregnancy. The same method was used in the analysis of the data obtained from the IVGTT. The Student's- $t$-test for paired data obtained from each subject's time zero measurements was used in the Lipiphysan ${ }^{\circledR}$ heparin experiments. The probability values were taken from two-tailed tables and only the values of $p<0.05$ were considered significant.

\footnotetext{
${ }^{1}$ Antiserum $30 \mathrm{~K}$ was long considered to be "specific for pancreatic glucagon" since it did not cross-react to a significant degree with the gut-glucagon-like immunoreactive material or enteroglucagon present in gut extracts. It is now well established that antiserum $30 \mathrm{~K}$ also reacts with a material present in certain parts of the gastrointestinal tract, mainly the antrum of the stomach, and which is, by all criteria used, indistinguishable from pancreatic glucagon [14].
}

Table 1. Blood glucose, plasma glucagon, insulin and free fatty acid (FFA) levels in nonpregnant control women (controls) and in pregnant women at various stages of pregnancy ${ }^{p}$

\begin{tabular}{|c|c|c|c|c|}
\hline & & \multicolumn{3}{|c|}{ Pregnant Women: Weeks of Pregnancy } \\
\hline & Controls & 5 th to 16 th & 17 th to 28 th & 29 th to 40 th \\
\hline $\begin{array}{l}\text { Blood glucose } \mathrm{b}^{\mathrm{b}} \\
\mathrm{mg} / 100 \mathrm{ml}\end{array}$ & $64.1 \pm 1.6$ & $\begin{array}{l}87.2 \pm 3.0^{\mathrm{d}} \\
(47)\end{array}$ & $\begin{array}{l}81.9 \pm 1.7^{\mathrm{d}} \\
(54)\end{array}$ & $\begin{array}{l}83.7 \pm 2.1^{\mathrm{d}} \\
(55)\end{array}$ \\
\hline Plasma glucagon ${ }^{\mathrm{b}}$ & $98.7 \pm 17.6$ & $115.5 \pm 9.2$ & $146.9 \pm 12.1^{c}$ & $97.2 \pm 8.8$ \\
\hline $\begin{array}{l}\mathrm{pg} / \mathrm{ml} \\
\text { Plasma insulin }\end{array}$ & $\begin{array}{l}\text { (9) } \\
4.9 \pm 1.1\end{array}$ & $\begin{array}{l}(35) \\
14.6 \pm 1.7^{\mathrm{d}}\end{array}$ & $\begin{array}{l}(43) \\
20.8 \pm 2.1^{\mathrm{d}}\end{array}$ & $\begin{array}{l}(51) \\
24.9 \pm 2.7^{d}\end{array}$ \\
\hline $\begin{array}{l}\mathrm{Plasma} \text { insulin } \\
\mu \mathrm{U} / \mathrm{ml}\end{array}$ & $\begin{array}{l}4.9 \pm 1.1 \\
(13)\end{array}$ & $(39)$ & $(47)$ & $(44)$ \\
\hline $\begin{array}{l}\text { Plasma FFA } \\
\mathrm{uEq} / \mathrm{l}\end{array}$ & $\begin{array}{l}396 \pm 105 \\
(8)\end{array}$ & $\begin{array}{l}414 \pm 26 \\
(41)\end{array}$ & $\begin{array}{l}425 \pm 24 \\
(45)\end{array}$ & $\begin{array}{l}452 \pm 24 \\
(48)\end{array}$ \\
\hline
\end{tabular}

a All samples were collected 2-4 hours following lunch

b All results are expressed as mean \pm standard error of the mean (SEM); the number of samples is indicated in parentheses

${ }^{c}$ corresponds to $p<0.05$ and ${ }^{d}$ to $p<0.01$ versus controls 


\section{Results}

\section{Changes in Metabolic and Hormonal Variables Associated with Pregnancy}

In the non-pregnant control women, the average blood glucose level measured 2-4 hrs following lunch was $64.1 \mathrm{mg} / 100 \mathrm{ml}( \pm 1.6, \mathrm{SEM})$; while the plasma FFA, insulin and glucagon levels were $396 \mu \mathrm{Eq} / 1( \pm$ $105, \mathrm{SEM}), 4.9 \mu \mathrm{U} / \mathrm{ml}( \pm 1.1, \mathrm{SEM})$ and $98.7 \mathrm{pg} / \mathrm{ml}$ $( \pm 17.6$, SEM) respectively.

Table 1 shows that under similar conditions, blood glucose values obtained from pregnant women were slightly but significantly higher than those of the controls throughout pregnancy, while plasma FFA values were essentially similar. Plasma insulin rose progressively during pregnancy and reached its maximum during the last trimester. As also shown in Table 1, the average glucagon values obtained during the 5 th to 16 th week or the 29 th to 40 th week of pregnancy did not differ significantly from the levels found in non-pregnant women. However, the glucagon values obtained during the 17 th to 28 th week of pregnancy were significantly increased. The average of all the plasma glucagon values obtained during this period from the pregnant group was $146.9 \pm 12.1 \mathrm{pg} / \mathrm{ml}$ $(\mathrm{n}=43)$, which is significantly higher than that of the control group $(p<0.05)$ and that of the pregnant women during the first $(p<0.02)$ or the third trimester $(p<0.001)$. The insulin: glucagon molar ratio rose progressively during pregnancy; it equalled 1.19 in the control group, while in the pregnant group it was 3.03 in the first, 3.40 in the second, and 6.15 in the last trimester.

\section{Intravenous Glucose Tolerance Test (IVGTT) Studies}

The results of these studies are illustrated in Fig. 1. The peak blood glucose values after IVGTT were significantly higher in the pregnant than in the control group $(271 \pm 14 \mathrm{mg} / 100 \mathrm{ml}$ versus $197 \pm 11 \mathrm{mg} / 100$ $\mathrm{ml}$ respectively, $p<0.001)$. The glucose assimilation coefficients $K[16]$ were not statistically different: 1.55 \pm 0.16 (SEM) in the control versus $1.84 \pm 0.21$ (SEM) in the pregnant group. As shown in Fig. 1, the insulin response to intravenous glucose was much higher in the pregnant than in the control group. The decreases in plasma FFA levels were similar in both groups and no significant differences were recorded. In the control group glucose injection was followed by a gradual decline in plasma glucagon levels, which reached its nadir ( $50 \%$ of the initial value) at the 40 th minute of the test. In contrast, glucagon
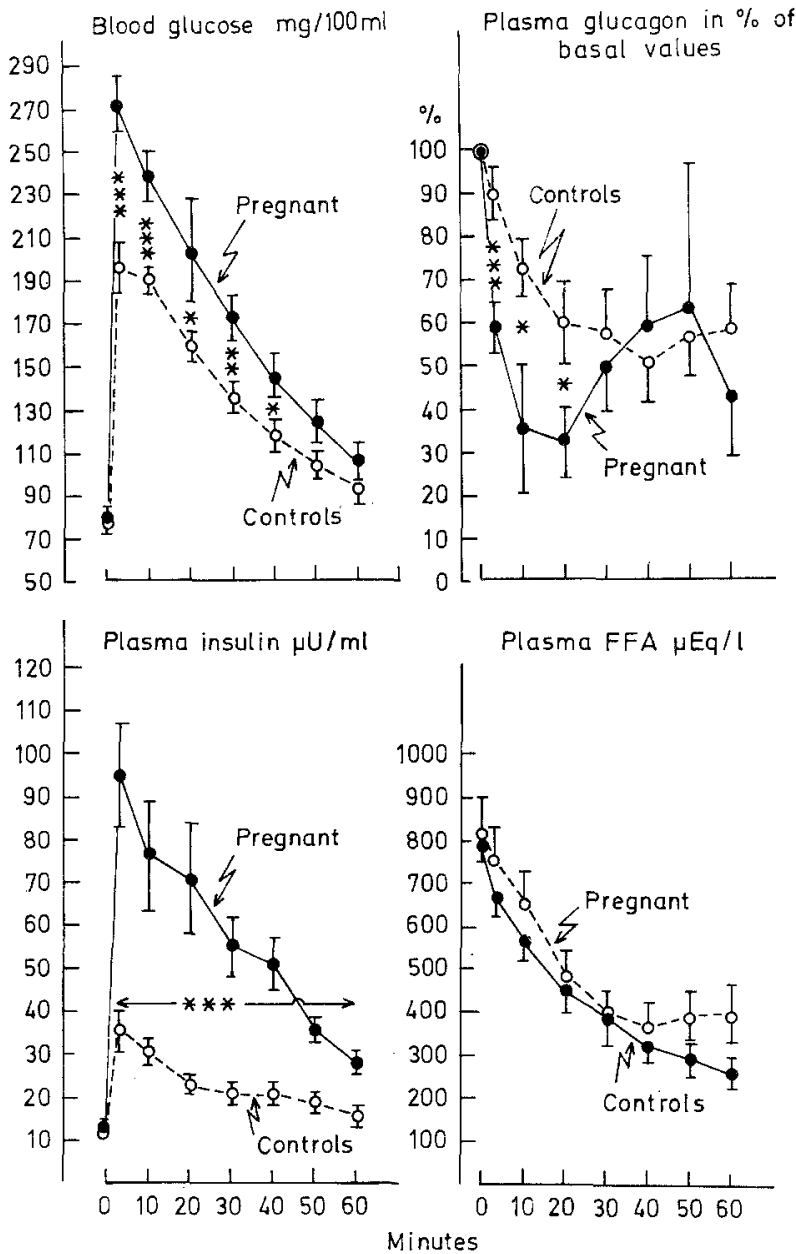

Fig. 1. Changes in blood glucose, plasma insulin, glucagon and FFA induced by intravenous glucose $(0.33 \mathrm{~g} / \mathrm{kg}$ body weight $)$ in 12 control $(\circ-0)$ and 8 pregnant $(\bullet \bullet)$ women. Results are expressed as mean \pm standard error of the mean (SEM) $X X X$, $X X$ and $X$ correspond to $p<0.01,0.02$ and 0.05 respectively. Because of wide individual variations, data of plasma glucagon are reported as \% of basal values. Mean basal plasma glucagon values averaged $108.7 \pm$ $14.6(\mathrm{SEM})$ and $105.3 \pm 26.2(\mathrm{SEM}) \mathrm{pg} / \mathrm{ml}$ in control and pregnant group, respectively

Table 2. Mean insulin: glucagon molar ratios during intravenous glucose tolerance test in non-pregnant control women and in pregnant women during the last trimester of pregnancy

\begin{tabular}{lcrrrrrrr}
\hline Time (minutes) & 0 & 3 & 10 & 20 & 30 & 40 & 50 & 60 \\
\hline Control Women & 2.5 & 7.9 & 7.4 & 5.9 & 5.7 & 6.1 & 4.7 & 4.1 \\
Pregnant Women & 2.7 & 30.7 & 28.1 & 31.9 & 22.5 & 16.2 & 6.9 & 9.4
\end{tabular}

a The insulin: glucagon molar ratios were calculated on the average insulin and glucagon plasma concentrations at each time of the test according to the formula

$\mathrm{I}: \mathrm{G}=\frac{[\text { insulin] } \mu \mathrm{U} / \mathrm{ml}}{\text { [glucagon] } \mathrm{pg} / \mathrm{mI}} \times 23.3 ; 23.3$ corresponding to the

biological potency of the human insulin used as standard: $23.3 \mathrm{U}$ per mg. 
levels decreased more rapidly and to a greater extent in pregnant women, as the lowest value equalled $32 \%$ of the initial value and was reached at the 20 th minute. The fasting insulin: glucagon molar ratio was similar in both groups (2.7 in the pregnant versus 2.5 in the control group); following glucose administration the ratio rose to a significantly greater degree in the pregnant group (Table 2).

\section{Triglyceride-Heparin Infusion Studies}

The results of these investigations are depicted in Fig. 2. The infusion of the lipid emulsion for $15 \mathrm{~min}$ before heparin administration in pregnant women



INSULIN $\mu U / m l$
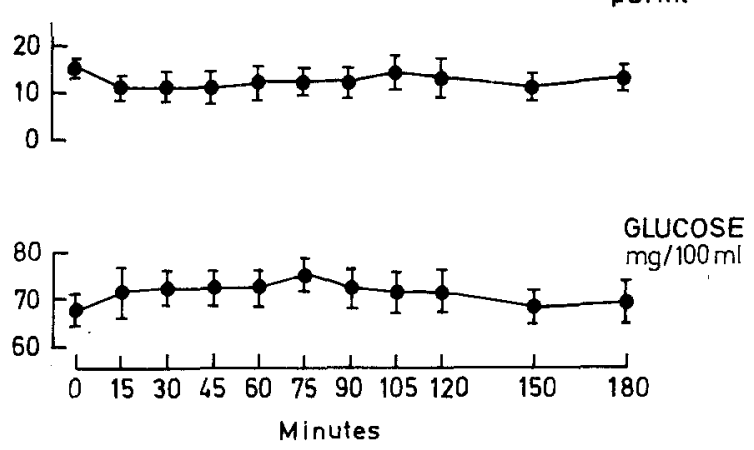

Fig. 2. Changes in plasma FFA, glucagon, insulin and blood glucose induced in 6 pregnant women by the intravenous infusion of Lipiphysan $^{\circledR}(1 \mathrm{ml} / \mathrm{min}$ from 0 to $75 \mathrm{~min})$ supplemented with $5000 \mathrm{U}$ intravenous heparin $15 \mathrm{~min}$ after the perfusion was begun. Results are expressed as mean \pm standard error of the mean (SEM). The Student's- $t$-test for paired data obtained from each subject's time 0 measurement was used. $\mathrm{XXX}, \mathrm{X} X$ and $\mathrm{X}$ correspond to $p<0.001$, 0.01 and 0.02 respectively caused only an insignificant rise in plasma FFA and did not affect plasma glucagon levels. However, when $5000 \mathrm{U}$ of heparin were injected intravenously, a rapid, significant and prolonged increase in FFA levels was observed, reaching an average value of about $2200 \mu \mathrm{Eq} / \mathrm{l}$ and remaining significantly elevated until the end of the observation period. This increase in plasma FFA levels was associated with a clearcut and significant decrease in peripheral plasma glucagon levels. Plasma glucagon remained suppressed until the FFA levels descended below $1200 \mu \mathrm{Eq} / \mathrm{l}$. Fig. 2 also clearly illustrates the opposing changes in plasma FFA and glucagon levels. Blood glucose and plasma insulin were not significantly modified during the test.

\section{Discussion and Conclusions}

The first and only study thus far ${ }^{2}$ on glucagon secretion in relation with pregnancy in human beings was recently reported by Daniel et al. [17]. These authors essentially showed [1] that plasma glucagon after an overnight fast in normal women in late pregnancy (30th to 40th week) was the same as that in age-matched, nongravid nullipara, [2] that following oral glucose administration, plasma glucagon in normal subjects fell to a greater degree antepartum than postpartum and [3], that in gestational diabetics, oral glucose also elicited suppression of glucagon antepartum, whereas suppressibility was not seen postpartum. The present study reports several new observations concerning plasma glucagon values throughout normal human pregnancy.

Our longitudinal survey of glucagon levels during pregnancy showed that the plasma concentrations during the first and last trimester of pregnancy were practically identical to those seen in non-pregnant women. This observation suggests that glucagon plays a small or insignificant role in the insulin resistance of pregnancy and that $\mathrm{hPL}$, whose secretion is maximal during the last trimester of pregnancy, does not stimulate the $\mathrm{A}_{2}$ cells under physiological conditions. A modest but significant glucagon rise was noted only during the second trimester, when neither insulin resistance nor hPL concentrations have reached their maximal values. It may be suggested that the trend towards hyperglucagonemia is counteracted by the increasing hyperinsulinemia during the third trimester. In rats, no change (in plasma glucagon) was seen

\footnotetext{
${ }^{2}$ Part of the data published by Daniel et al. [17] were briefly reported by Freinkel at the 8 th Congress of the International Diabetes Federation and summarized in the corresponding Proceedings [31].
} 
in fed pregnant animals at midgestation, but a significant $40 \%$ increase was observed in late gestation [18]. Curiously, the glucagon response to alanine in pregnancy was nearly sevenfold greater than in control fed rats, but pregnancy entirely eliminated the glucagon response to fasting hypoglycemia [18].

Another conclusion of the present study is that intravenous administration of glucose induced a more rapid and more profound reduction in plasma glucagon concentrations in pregnant than in non-pregnant women. Like Daniel et al. [17], we suggest that this increased suppressibility of circulating glucagon may be linked to the exaggerated hyperglycemia and hyperinsulinemia that occur during the glucose tolerance test in late pregnancy. These data lend further support to the concept that insulin plays an important role in the physiologic sensitivity of the A-cell to glucose $[1,2,19,20]$. The hyperinsulinism, hypersuppressibility of glucagon and the consequently elevated insulin: glucagon molar ratio can be interpreted teleologically as an attempt by the maternal organism to increase its energy stores and thus maintain its own anabolic activities, compensating in this way for the "accelerated starvation" [21], due to the transfer of substrates to the foetus, which occurs in theinterprandial periods. Metzger et al. [22] also found a raised I:G molar ratio in pregnant well nourished rats when compared with non-pregnant controls. This was likewise interpreted as a way of maintaining the mother's energy stores, since it is known that chronic administration of glucagon increases catabolism in pregnant [23-24] as well as in non-gravid animals [25].

Finally, our data suggest that, in pregnancy, changes in circulating FFA levels affect glucagon secretion in a manner similar to the one reported under other conditions in vitro $[1,26,27]$ and in vivo, in dogs $[1,28,29]$ and humans [30].

Acknowledgments. This work was supported in part by the Fonds de la Recherche Scientifique Médicale (F.R.S.M.) and the Fonds National de la Recherche Scientifique (F.N.R.S.) of Belgium. We acknowledge with thanks $D$. Binder for his help during the preparation of this manuscript. E. Vaessen-Petit for her secretarial assistance, C. Cartenstadt, Y. Claessens and M. E. Loumaye for their technical assistance and the medical and nursing staff of the Department of Obstetrics for their skilled assistance.

\section{References}

1. Luyckx, A.S.: Etude de la sécrétion de l'insuline et du glucagon. Paris: Masson 1974

2. Unger, R.H., Orci, L.: The essential role of glucagon in the pathogenesis of diabetes mellitus. Lancet $1975 \mathrm{I}, 14-16$

3. Spellacy, W.N., Goetz, F.C.: Plasma insulin in normal late pregnancy. New Engl. J. Med. 268, 982-994 (1963)
4. Bleicher, S.J., O'Sullivan, J.B., Freinkel, N.: Carbohydrate metabolism in pregnancy. $V$. The interrelations of glucose, insulin and free fatty acids in late pregnancy and postpartum. New Engl. J. Med. 271, 866-872 (1964)

5. Kalkhoff, R., Schalch, D.S., Walker, J.L., Beck, P., Kipnis, D.M., Daughaday, W.H.: Diabetogenic factors associated with pregnancy. Trans. Ass. Amer. Phycns 77, 270-279 (1964)

6. Laube, H., Fussgänger, R.D., Schröder, K.E., Pfeiffer, E.F.: Acute effect of human chorionic somatomammotropin on insulin and glucagon release in the isolated perfused pancreas. Diabetes 21, 1072-1076 (1972)

7. Unger, R.H., Lefebvre, P.J.: Glucagon Physiology. In: Glucagon molecular physiology, clinical and therapeutic implications (eds. P.J. Lefebvre, R.H., Unger), pp. 213-244. Oxford: Pergamon Press 1972

8. Gaspard, U.J., Sandront, H.M., Luyckx, A.S., Lefebvre, P.J.: Hormonal and metabolic changes induced by elevated plasma free fatty acids in term pregnancy. I. Effect on maternal blood glucose, insulin and human placental lactogen circulating levels. J. clin. Endocr. 40, 1066-1072 (1975)

9. Hoffman, W.S.: A rapid photoelectric method for the determination of glucose in blood and urine. J. biol. Chem. 120, 51-55 (1937)

10. Dole, V.P., Meinertz, H.: Microdetermination of long chain fatty acids in plasma and tissues. J. biol. Chem. 235, 2595-2599 (1960)

11. Quabbe, H.J.: Modifikation der radioimmunolgischen Insulinbestimmung nach Hales und Randle. Diabetologia 5, 101-107 (1969)

12. Hales, C.N., Randle, P.J.: Immunoassay of insulin with insulinantibody precipitate. Biochem. J. 88 137-146 (1963)

13. Luyckx, A.S.: Immunoassays for glucagon. In : Glucagon molecular physiology, clinical and therapeutic implications (eds. P.J. Lefebvre, R.H. Unger), pp 285-298. Oxford: Pergamon Press 1972

14. Sasaki, H., Rubalcava, B., Srikant, C.B., Baetens, D., Orci, L., Unger, R.H.: Gut Glucagonoid (GLI) and gut glucagon. Proc. Internat. Symposium on Gastrointestinal Hormones, Galvestone, Oct. 1974 (in press)

15. Snedecor, G.W.: Statistical methods. The Iowa State University Press, 5th edition, 1966

16. Conard, V.: Mesure de l'assimilation du glucose. Bases théoriques et applications cliniques. Brussels: Acta Medica Belgica 1955

17. Daniel, R. R., Metzger, B.E., Freinkel, N., Faloona, G. R., Unger, R.H., Nitzan, M.: Carbohydrate metabolism in pregnancy. XI. Response of plasma glucagon to overnight fast and oral glucose during normal pregnancy and in gestational diabetes. Diabetes 23, 771-776 (1974)

18. Saudek, C.D., Finlowski, M., Knopp, R.H.: Plasma glucagon and insulin in rat pregnancy. J. clin. Invest. 55, 180-187 (1975)

19. Luyckx, A.S., Massi-Benedetti, F., Falorni, A., Lefebvre, P.J.: Presence of pancreatic glucagon in the portal plasma of the human neonates. Differences in insulin and glucagon responses to glucose between normal infants and infants from diabetic mothers. Diabetologia 8, 296-300 (1972)

20. Massi-Benedetti, F., Falorni, A., Luyckx, A.S., Lefebvre, P.J.: Inhibition of glucagon secretion in the human newborn by simultaneous administration of glucose and insulin. Horm. Metab. Res. 6, 392-396 (1974)

21. Freinkel, N.: Effect of the conceptus on maternal metabolism during pregnancy. In: On the nature and treatment of diabetes mellitus (eds. B.S. Leibel, G.A. Wrenshall), p. 679. Amsterdam: Excerpta Medica Foundation 1965

22. Metzger, B., Pek, S., Hare, J., Freinkel, N.: Relationships be- 
tween glucose, insulin and glucagon during fasting in late gestation in the rat. Life Sci. 15, 301-308 (1974)

23. Curry, D.M., Beaton, G.H.: Glucagon administration in pregnant rats. Endocrinology 63, 252-254 (1958)

24. Tyson, J.E., Kinch, R.A.H., Stevenson, J.A.F.: Effect of cortisone and glucagon on rat gestation. Amer. J. Obstet. Gynec. 106, 656-659 (1970)

25. Kalant, H.: Metabolic effects of the pancreatic hyperglycemic factor. Proc. Soc. exp. Biol. (N.Y.) 86, 617-619 (1954)

26. Edwards, J.C., Taylor, K.W.: Fatty acids and the release of glucagon from isolated guinea-pig islets of Langerhans incubated in vitro. Biochim. biophys. Acta (Amst.), 215, 310-315 (1970)

27. Luyckx, A.S., Lefebvre, P.J.: The role of energy substrates in controlling glucagon secretion: Experimental studies. In: Diabetes, Proc. 8th Congress Internat. Diabetes Fed. (eds. W.J. Malaisse, J. Pirart), p. 190. Amsterdam: Excerpta Medica 1974

28. Seyffert, W.A., Jr, Madison, L.L.: Physiologic effects of metabolic fuels on carbohydrate metabolism. I.: Acute effect of elevated plasma free fatty acids on hepatic glucose output, peripheral glucose utilization, serum insulin and plasma glucagon levels. Diabetes 16, 765-776 (1967)
29. Luyckx, A.S., Lefebvre, P.J.: Arguments for a regulation of pancreatic glucagon secretion by circulating plasma free fatty acids. Proc. Soc. exp. Biol. (N.Y.) 133, 524-528 (1970)

30. Gerich, J.E., Langlois, M., Schneider, V., Karam, J.H., Noacco, C.: Effects of alterations of plasma free fatty acid levels on pancreatic glucagon secretion in man. J. clin. Invest. 53, 1284-1289 (1974)

31. Freinkel, N., Metzger, B. E., Nitzan, M., Daniel, R., Surmaczynska, B.Z., Nagel, T.C.: Facilitated anabolism in late pregnancy: Some novel maternal compensations for accelerated starvation. In: Diabetes. Proc. 8th Congress Internat. Diabetes Fed. (eds. W.J. Malaisse, J. Pirart,), p. 474. Amsterdam: Excerpta Medica 1974

Dr. A.S. Luyckx

Secteur Diabetologie

Institute de Médicine

Université de Liège

Boulevard de la Constitution, 66

B-4000 Liège

Belgium 